\title{
Synthesis of Air-Stable Pd(o) Catalyst Bearing Donor and Acceptor Phosphine Ligands
}

\author{
Ryota Sato, Takaki Kanbara*, Junpei Kuwabara*
}

Tsukuba Research Center for Energy Materials Science (TREMS), Graduate School of Pure and Applied Sciences, University of Tsukuba, 1-1-1 Tennodai, Tsukuba, Ibaraki 305-8573, Japan

\begin{abstract}
We synthesized a new $\mathrm{Pd}(0)$ complex bearing $\pi$-acceptor ligands and a $\sigma$-donor ligand and confirmed that it can exhibit high air stability and catalytic activity in direct arylation reactions. Moreover, stoichiometric reactions of the complex revealed that a $\sigma$-donor ligand does not dissociate from the Pd center.
\end{abstract}

Transition-metal-catalyzed cross-coupling reactions are effective methods to construct C-C or C-hetero atom bonds. ${ }^{1-3}$ Various precursors and ligands of $\mathrm{Pd}$ catalysts have been developed and used in many types of coupling reactions. $\mathrm{Bi}$ - or zero-valent $\mathrm{Pd}$ complexes are used as Pd catalyst precursors. ${ }^{4}$ Since Pd(II) complexes have high air stability, they can be easily handled and stored in air atmosphere (Figure 1a). However, the process of forming a catalytic active $\operatorname{Pd}(0)$ species causes decomposition of substrates or ligands at the initial stage of cross-coupling reactions. ${ }^{5-7}$ To solve this problem, many efforts have been devoted to the development of Pd(II) complexes that can be smoothly reduced to $\operatorname{Pd}(0)$ active species without the decomposition of substrates or ligands. ${ }^{8-10}$ Because $\operatorname{Pd}(0)$ complexes have the same oxidation state as catalytic active species, they do not cause the decomposition reactions. (Figure 1b). However, $\operatorname{Pd}(0)$ complexes are generally unstable in air. ${ }^{11}$ Multidentate ligands have been studied to provide air stability to $\operatorname{Pd}(0)$ complexes. ${ }^{12-14}$ Recentry, Soós and co-workers have developed an air-stable $\operatorname{Pd}(0)$ complex, Superstable $\mathrm{Pd}$ catalyst $\left(\mathrm{Pd}\left[\mathrm{P}\left\{3,5-\left(\mathrm{CF}_{3}\right)_{2} \mathrm{C}_{6} \mathrm{H}_{3}\right\}_{3}\right]_{3}=\mathrm{SSPd}\right)$, which bears three $\pi$-acceptor phosphine ligands (Figure 1c). ${ }^{15}$ The ligands decrease electron density of the Pd center to suppress oxidation of $\mathrm{Pd} .{ }^{16}$ In catalytic reactions, strong electrondonating phosphine ( $\sigma$-donor) ligands with steric bulkiness are preferred to achieve a high catalytic activity. ${ }^{17}$ Therefore, we designed a new $\operatorname{Pd}(0)$ catalyst precursor bearing a $\sigma$-donor ligand to impart catalytic activity and a $\pi$-acceptor ligand to provide air stability (Figure 1d). During a catalytic reaction, the $\pi$-acceptor ligands may selectively dissociate from the Pd center because of their weak coordination ability compared with that of the $\sigma$-donor ligand. Herein, we synthesize a novel $\operatorname{Pd}(0)$ complex and determine its stability and catalytic activity for the direct $\mathrm{C}-\mathrm{H}$ arylation reaction. ${ }^{3}$

The target $\operatorname{Pd}(0)$ complex was synthesized from SSPd through a ligand exchange reaction with tricyclohexylphosphine $\left(\mathrm{PCy}_{3}\right)$ in $68 \%$ yield (Scheme 1$)$. The reaction of SSPd with 1 equivalent of $\mathrm{PC}_{3}$ afforded a mixture of Complex 1 and residual SSPd. The quantitative formation of Complex 1 was observed in the reaction with 2 equivalents of $\mathrm{PCy}_{3}$ or an ex- cess of $\mathrm{PCy}_{3}$. The structure of Complex 1 might be thermodynamically stable in terms of steric and electronic aspects.

(a) $\mathrm{Pd}$ (II) catalyst precursors

$\mathrm{Pd}(\mathrm{OAC})_{2}+\mathrm{PR}_{3} \quad \mathrm{PdCl}_{2}\left(\mathrm{PR}_{3}\right)_{2}$

(b) $\operatorname{Pd}(0)$ catalyst precursors

$\mathrm{Pd}\left(\mathrm{PPh}_{3}\right)_{4} \quad \mathrm{Pd}\left(\mathrm{PCy}_{3}\right)_{2} \quad \mathrm{Pd}_{2}(\mathrm{dba})_{3}+\mathrm{PR}_{3}$

(c) Air-stable $\mathrm{Pd}(0)$ catalyst precursor<smiles>CCP(C)C(C)(C)c1cc(C(F)(F)F)cc(C(F)(F)F)c1</smiles>

(d) This work

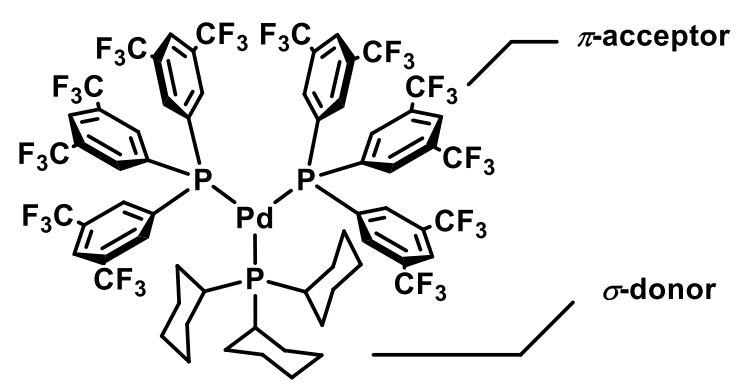

Figure 1. Various Pd catalyst precursors. 


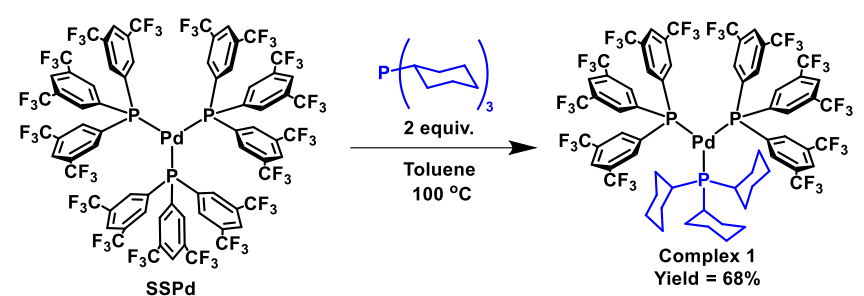

Scheme 1. Synthesis of Complex 1.

Doublet and triplet signals with an integral value of 2:1 were observed through ${ }^{31} \mathrm{P}$ NMR spectroscopy (Figure S2). These signals indicate that the $\mathrm{Pd}(0)$ complex possesses two types of phosphine ligands in 2:1 ratio. To obtain detailed structural information, single crystal X-ray analysis was conducted (Figure 2).

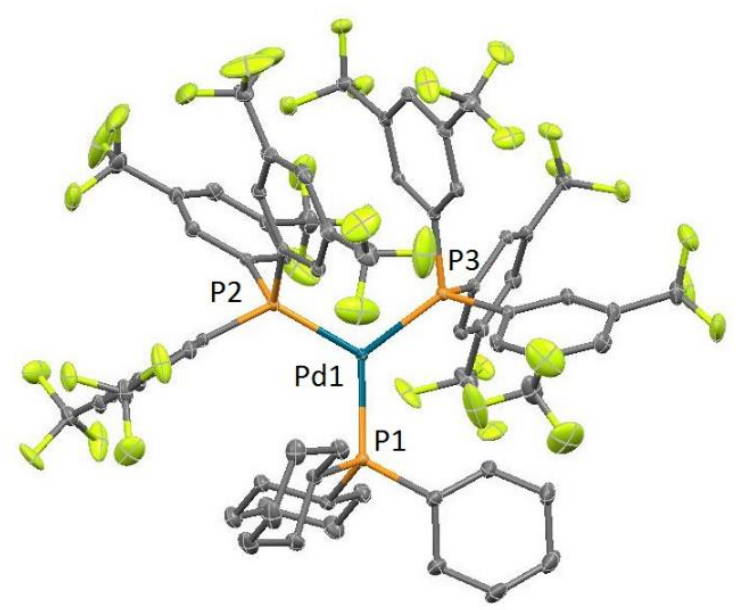

Figure 2. ORTEP drawing of Complex 1 with thermal ellipsoids at $30 \%$ probability level. All hydrogen and disordered fluorine atoms are omitted for clarity. Selected bond lengths $(\AA): \mathrm{Pd} 1-\mathrm{P} 1=2.3565(8), \mathrm{Pd} 1-\mathrm{P} 2=2.2856(8), \mathrm{Pd} 1-\mathrm{P} 3=$ 2.3565(8). Selected bond angles $\left({ }^{\circ}\right)$ : P1-Pd1-P2 $=119.16(3)$, P1-Pd-P3 = 126.71(3), P2-Pd1-P3 = 113.31(3).

The structure with a $\sigma$-donor phosphine ( $\left.\mathrm{PCy}_{3}\right)$ and two $\pi$ acceptor phosphines $\left(\mathrm{P}\left\{3,5-\left(\mathrm{CF}_{3}\right)_{2} \mathrm{C}_{6} \mathrm{H}_{3}\right\}_{3}\right)$ is consistent with the ${ }^{31} \mathrm{P}$ NMR spectroscopy results. The bond length of Pd1-P1 $(2.3565(8) \AA$ ) was longer than those of Pd1-P2 and Pd1-P3 (2.2856(8) and 2.3565(8) $\AA$ ). The long Pd1-P1 length is presumably due to the presence of bulky cyclohexyl groups in PCy3. ${ }^{18}$ In addition, back donation from Pd to the $\pi$-acceptor phosphines may result in short Pd1-P2 and Pd1-P3 bonds.

To prove our concept, the air stability of Complex 1 was evaluated and compared with that of other $\operatorname{Pd}(0)$ complexes. Complex $1 \mathrm{did}$ not decompose in air at room temperature for a month, which was confirmed by ${ }^{31} \mathrm{P}$ NMR spectroscopy (Figure S3). This observation verifies that Complex 1 has good air stability, which enables its storage and handling in air. Accelerated aging tests were conducted to evaluate air stability under harsh conditions (in air, $60^{\circ} \mathrm{C}$, Figure 3). Because the color of $\left.\mathrm{Pd}(\mathrm{PCy})_{2}\right)_{2}$ turned to black for $1 \mathrm{~h}, \mathrm{Pd}\left(\mathrm{PCy}_{3}\right)_{2}$ was decomposed under the tested condition (Figure S4). In contrast, Complex 1 and SSPd showed no color change. The $\pi$-acceptor ligand, $\mathrm{P}\left\{3,5-\left(\mathrm{CF}_{3}\right)_{2} \mathrm{C}_{6} \mathrm{H}_{3}\right\}_{3}$, decreased the electron-density of the Pd center of Complex 1 and imparted high air and thermal stability similar to those of SSPd.

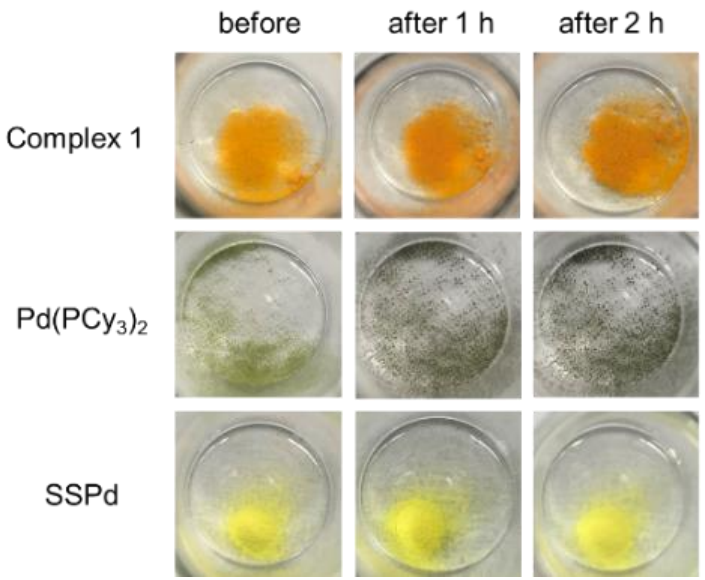

Figure 3. Accelerated aging test (in air, $60^{\circ} \mathrm{C}$ ).

Subsequently, Complex 1 was used as a catalyst for direct C-H arylation reactions. ${ }^{19}$ We optimized a loading amount of the $\operatorname{Pd}(0)$ complex (Table 1). The reactions with $2 \mathrm{~mol} \%$ and 0.5 mol\% of Complex 1 afforded efficient product formation (Entries 1 and 2). Meanwhile, $0.25 \mathrm{~mol} \%$ of Pd loading could not give full conversion of the reaction (Entry 3 ). Therefore, 0.5 mol\% (Entry 2) was considered as the optimal catalyst loading.

Table 1. Direct arylation of 2-thiophenecarbonitrile with 4bromoanisole by Complex 1

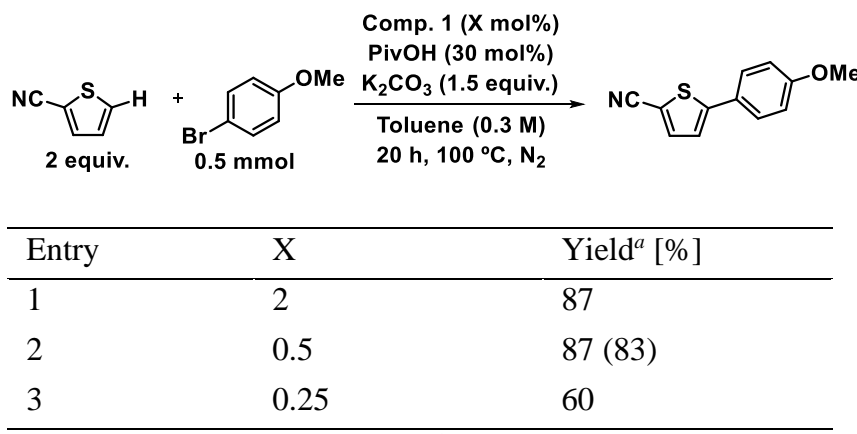

${ }^{a}$ The yield was determined by ${ }^{1} \mathrm{H}$ NMR analyses of a crude product with ferrocene as an internal standard. Number in parentheses is the isolated yield.

To compare the catalytic activity, time conversion of the reaction with the $\operatorname{Pd}(0)$ catalysts was investigated (Figure 4). The $\mathrm{Pd}\left(\mathrm{PCy}_{3}\right)_{2}$ system showed good catalytic activity in the initial stage. However, the catalytic activity decreased during the reaction. The relatively low catalyst loading $(0.5 \mathrm{~mol} \%)$ resulted in the recognizable decomposition of the catalyst. Although the reactions with Complex 1 and SSPd showed induction periods, these catalytic systems showed high catalytic activity in the middle to late stages of the reactions. Because the catalytic activity of Complex 1 was better than that of $\mathrm{SSPd}, \mathrm{PCy}_{3}$ in Complex 1 can be considered to provide a positive effect on the catalytic reaction. 


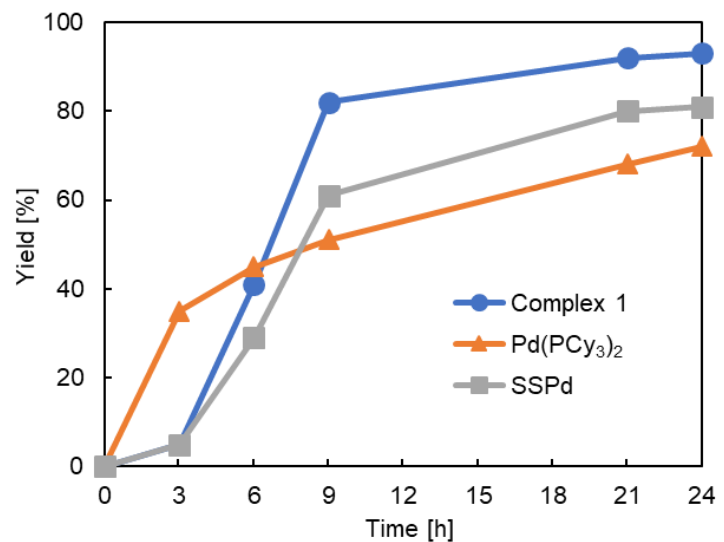

Figure 4. Time conversions of direct arylation reaction by various $\mathrm{Pd}(0)$ catalyst precursors. Conditions: $\mathrm{Pd}=0.0025$ mmol, 4-bromoanisole $=0.50 \mathrm{mmol}, 2$-thiophenecarbonitrile $=$ $1.0 \mathrm{mmol}, \mathrm{PivOH}=0.15 \mathrm{mmol}, \mathrm{K}_{2} \mathrm{CO}_{3}=0.75 \mathrm{mmol}$, toluene $=1.7 \mathrm{~mL}$, temp. $=100{ }^{\circ} \mathrm{C}$. Yield was determined by ${ }^{1} \mathrm{H}$ NMR analysis of a crude product with ferrocene as an internal standard.

A stoichiometric reaction of Complex 1 was conducted to determine the reason for high catalytic activity of Complex $1 .^{20}$ An oxidative addition reaction is the first step of the direct arylation reaction (Scheme $\mathrm{S} 1$ ). The model reaction of the oxidative addition reaction afforded a $\mathrm{Pd}(\mathrm{II})$ complex bearing $\mathrm{PCy}_{3}$ and $\mathrm{P}\left\{3,5-\left(\mathrm{CF}_{3}\right)_{2} \mathrm{C}_{6} \mathrm{H}_{3}\right\}_{3}$ ligand (Complex 2 in Scheme 2). ORTEP drawing of Complex 2 showed that one of the $\pi$ acceptor ligands is selectively dissociated and $\mathrm{PCy}_{3}$ remains on the Pd center in the oxidative addition reaction (Figure 5). This result supports our hypothesis that $\mathrm{PCy}_{3}$ remains on the Pd center during the catalytic reaction and provides good catalytic activity.

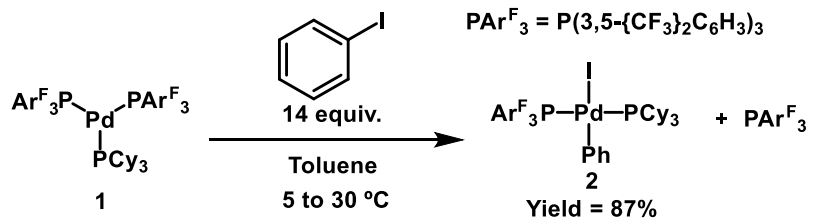

Scheme 2. Synthesis of Complex 2.

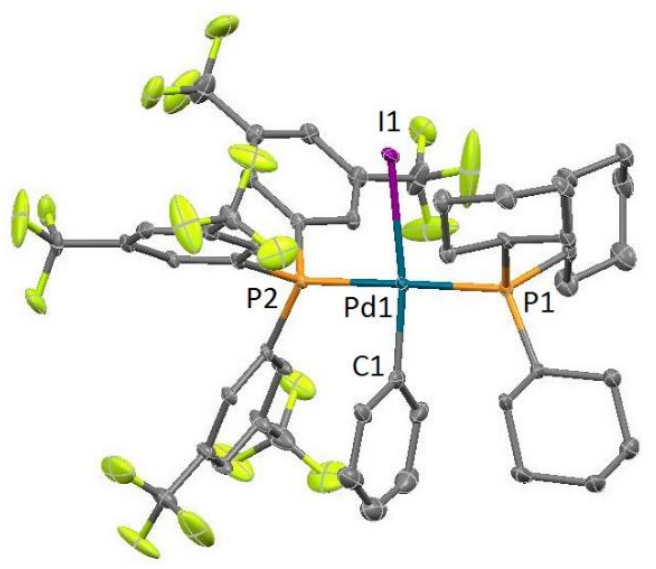

Figure 5. ORTEP drawing of Complex 2 with thermal ellipsoids at $30 \%$ probability level. All hydrogen atoms and incorporated molecules are omitted for clarity. Selected bond lengths $(\AA)$ : Pd1-P1 = 2.3524(13), Pd1-P2 = 2.3177(12), Pd1$\mathrm{I} 1=2.7003(5), \mathrm{Pd} 1-\mathrm{C} 1=1.995(6)$. Selected bond angles $\left({ }^{\circ}\right)$ : P1-Pd1-P2 = 179.04(5), P1-Pd-I1 = 95.25(3), P2-Pd1-I1 = 85.70(3), I1-Pd1-C1 = 171.23(16).

Furthermore, we tested a substrate scope in direct arylation under the optimized conditions (Table 2). The reactions with the catalyst $(0.5 \mathrm{~mol} \%)$ afforded the products in good to moderate yields (Entries 1-4). The yield can be further improved by optimization of the reaction conditions for each substrate.

In conclusion, we synthesized the novel air-stable $\operatorname{Pd}(0)$ complex bearing $\pi$-acceptor and $\sigma$-donor ligands. The $\operatorname{Pd}(0)$ complex is stable in air at $60{ }^{\circ} \mathrm{C}$ and serves as a good catalyst for the direct arylation reaction even with small amount of $\mathrm{Pd}$ loading. Additionally, Complex 1 shows a higher catalytic activity than that of other known $\operatorname{Pd}(0)$ complexes. A stoichiometric model reaction reveals that the $\sigma$-donor ligand imparts the high catalytic performance of Complex 1. The strategy of combining "stabilization" and "activation" gives stimulus for catalyst chemistry.

Table 2. Direct arylation reaction by Complex 1

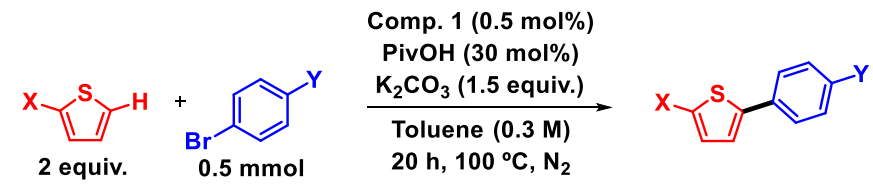

Entry

${ }^{a}$ The yield was determined by ${ }^{1} \mathrm{H}$ NMR analyses of a crude product with ferrocene as an internal standard.

\section{ASSOCIATED CONTENT}

Supporting Information

The Supporting Information is available free of charge on the ACS Publications website.

Experimental details, crystallographic data, and NMR spectra (PDF) 


\section{Accession Codes}

CCDC 1950053-1950054 contain the supplementary crystallographic data for this paper. These data can be obtained free of charge via www.ccdc.cam.ac.uk/data_request/cif, or by emailing data_request@ccdc.cam.ac.uk, or by contacting The Cambridge Crystallographic Data Centre, 12 Union Road, Cambridge CB2 1EZ, UK; fax: +44 1223336033.

\section{AUTHOR INFORMATION}

\section{Corresponding Author}

* E-mail: kanbara@ims.tsukuba.ac.jp

*E-mail: kuwabara@ims.tsukuba.ac.jp

\section{ORCID}

Takaki Kanbara: 0000-0002-6034-1582

Junpei Kuwabara: 0000-0002-9032-5655

\section{Notes}

The authors declare no competing financial interest.

\section{ACKNOWLEDGMENT}

The authors thank the Chemical Analysis Center of University of Tsukuba for the measurements of NMR spectra and elemental analysis. The authors are grateful to Prof. M. Ichinohe for lending his expertise on X-ray analysis. This study was supported by Grant-in-Aid for Scientific Research (17K05973, 17H03063) and Scientific Research on Innovative Areas (17H05141) from JSPS.

\section{REFERENCES}

Johansson Seechurn, C. C. C.; Kitching, M. O. Colacot, T. J.; Snieckus, V. Palladium-Catalyzed Cross-Coupling: A Historical Contextual Perspective to the 2010 Nobel Prize. Angew. Chem., Int. Ed. 2012, 51, 5062-5085.

Li, H.; Johansson Seechurn, C. C. C.; Colacot, T. J. Development of Preformed Pd Catalysts for CrossCoupling Reactions, beyond the 2010 Nobel Prize. ACS Catalysis 2012, 2, 1147-1164.

(3) Campeau, L. C.; Stuart, D. R.; Fagnou, K. Recent Advances in Intermolecular Direct Arylation Reactions. Aldrichimica Acta 2007, 40, 35-41. Alberico, D.; Scott, M. E.; Lautens, M. Aryl-Aryl Bond Formation by Transition-Metal-Catalyzed Direct Arylation. Chem. Rev. 2007, 107, 174-238.

Kuwabara, J.; Sakai, M.; Zhang, Q.; Kanbara, T. Mechanistic Studies and Optimisation of a PdCatalysed Direct Arylation Reaction Using Phosphine-Free Systems. Org. Chem. Front. 2015, 2, 520-525.

(6) Ozawa, F.; Kubo, A.; Hayashi, T. Generation of Tertiary Phosphine-Coordinated $\operatorname{Pd}(0)$ Species from $\mathrm{Pd}(\mathrm{OAc})_{2}$ in the Catalytic Heck Reaction. 1992, 21, 2177-2180.

Bao, Z.; Chan, W. K.; Yu, L. Exploration of the Stille Coupling Reaction for the Syntheses of Functional Polymers. J. Am. Chem. Soc. 1995, 117, 12426-12435.

Biscoe, M. R.; Fors, B. P.; Buchwald, S. L. A New Class of Easily Activated Palladium Precatalysts for Facile C-N Cross-Coupling Reactions and the Low Temperature Oxidative Addition of Aryl Chlorides. J. Am. Chem. Soc. 2008, 130, 66866687.

Bruno, N. C.; Tudge, M. T.; Buchwald, S. L. Design and Preparation of New Palladium Precatalysts for C-C and C-N Cross-Coupling Reactions. Chem. Sci. 2013, 4, 916-920.

Gioria, E.; del Pozo, J.; Martínez-Ilarduya, J. M.; Espinet, P. Promoting Difficult Carbon-Carbon Couplings: Which Ligand Does Best? Angew. Chem.,Int. Ed. 2016, 55, 13276-13280.

(11) Fantasia, S.; Nolan, S. P. A General Synthetic Route to Mixed NHC-Phosphane Palladium(0) Complexes $(\mathrm{NHC}=\mathrm{N}-$ Heterocyclic Carbene $)$. Chem. Eur. J. 2008, 14, 6987-6993.

Aizawa, S. I.; Majumder, A.; Yokoyama, Y.; Tamai, M.; Maeda, D.; Kitamura, A. Air-Stable, Recyclable, and Regenerative Phosphine Sulfide Palladium(0) Catalysts for C-C Coupling Reaction. Organometallics 2009, 28, 6067-6072.

Majumder, A.; Gupta, R.; Mandal, M.; Babu, M.; Chakraborty, D. Air-Stable Palladium(0) Phosphine Sulfide Catalysts for Ullmann-Type C-N and C-O Coupling Reactions. J. Organomet. Chem. 2015, 781, 23-34.

Sluijter, S. N.; Warsink, S.; Lutz, M.; Elsevier, C. J. Synthesis of Palladium(0) and -(II) Complexes with Chelating Bis(N-Heterocyclic Carbene) Ligands and Their Application in Semihydrogenation. Dalton. Trans. 2013, 42, 7365-7372.

Jakab, A.; Dalicsek, Z.; Holczbauer, T.; Hamza, A.; Pápai, I.; Finta, Z.; Timári, G.; Soós, T. Superstable Palladium(0) Complex as an Air-and Thermostable Catalyst for Suzuki Coupling Reactions. European J. Org. Chem. 2015, 2015, 60-66.

Korenaga, T.; Ko, A.; Uotani, K.; Tanaka, Y.; Sakai, T. Synthesis and Application of 2,6Bis(Trifluoromethyl)-4-Pyridyl Phosphanes: The Most Electron-Poor Aryl Phosphanes with Moderate Bulkiness. Angew. Chem., Int. Ed. 2011, 50, 10703-10707.

Barrios-Landeros, F.; Carrow, B. P.; Hartwig, J. F. Effect of Ligand Steric Properties and Halide Identity on the Mechanism for Oxidative Addition of Haloarenes to Trialkylphosphine $\operatorname{Pd}(0)$ 
Complexes. J. Am. Chem. Soc. 2009, 131, 8141-

8154.

(18) Bunten, K. A.; Chen, L.; Fernandez, A. L.; Poë, A. J. Cone Angles: Tolman's and Plato's. Coord.

Chem. Rev. 2002, 233-234, 41-51.

(19) Schipper, D. J.; Fagnou, K. Direct Arylation as a Synthetic Tool for the Synthesis of ThiopheneBased Organic Electronic Materials. Chem. Mater. 2011, 23, 1594-1600.

(20) Yamamoto, A.; Ozawa, F.; Kawasaki, N.; Okamoto, H.; Yamamoto, T. Mechanisms of Double and Single Carbonylation Reactions of Aryl Iodides Catalyzed by Palladium Complexes To Give AKeto Esters and Esters. Organometallics 1987, 6, 1640-1651. 